\title{
Effective recruitment strategies for the biotechnology industry
}

\author{
Automating human resource functions can be crucial in managing your employee base.
}

\author{
Debbie McGrath
}

n the competitive biotechnology industry, becoming an employer of choice involves extensive commitment to training, leadership, and employee development. The demand for qualified life science and healthcare professionals is the highest in years, and the forecast is only expected to increase. However, companies often make the mistake of thinking a large recruitment budget will strive to make them well known in their industry, when in fact the exact opposite can happen. You can be labeled as a churn-and-burn place if you have not addressed the needs of your current employee base and turnover becomes an issue.

\section{By the numbers}

The key to developing an effective recruitment strategy is in understanding several important measurements: How much does it cost to hire a new staff member, and what is the annual turnover across the company, across departments, and across staff levels. It is surprising how many firms do not have a solid understanding of what these numbers mean.

The turnover factor is most important, as it can pinpoint a leadership problem. The most common reason cited for high turnover is lack of leadership and the value one feels to a company. One also has to look at how your company's numbers compare with companies in the same industry sector and/or geographic area.

In the case of three hypothetical companies (see Table 1), Company 1 has a higher cost per hire than the industry average. If they could lower their cost per hire to the industry average, a net savings of $\$ 1.125$ million can be contributed to the bottom line. They should look at how their recruitment budget is allocated across various media (Internet, print, campus, outside consultants, etc.). In most cases, companies with a higher cost per average have a higher dependency on outside consultants. All efforts should be made to decrease their cost per hire.

Company 2, with a lower than industry average in turnover and cost per hire,

Debbie McGrath is founder and president of HR.com (dmcgrath@hr.com).

\begin{tabular}{lcccc}
\multicolumn{5}{l}{ Table 1. Measuring employee recruitment and retention of three companies } \\
& Company 1 & Company 2 & Company 3 & Industry average \\
\hline No. of hires/year & 750 & 500 & 1000 & 750 \\
No. of employees & 5000 & 5000 & 5000 & 5000 \\
Turnover & $15 \%$ & $10 \%$ & $20 \%$ & $15 \%$ \\
Cost per hire & $\$ 4500$ & $\$ 2700$ & $\$ 2300$ & $\$ 3000$
\end{tabular}

should focus on alternative measurements for improvement and try to standardize their practices, so they can consistently deliver above average results. Finally, if Company 3 can cut their number of new hires per year by working on retention strategy and bring their turnover down to industry average, they would save $\$ 575,000$ per year.

Developing effective recruitment and retention strategies can be done using the following principles:

- Use benchmark data and industry standards to establish industry goals. The Saratoga Institute, a leading human capital management company, provides 288 different human resource measurements by geography and industry. It is a must for any firm (http://www.saratoga-institute.com).

- Track the performance of recruitment vehicles and move more of your recruitment efforts online. The Internet is more cost effective, and you can generally get more value if you know the demographics of your local, national, and vertical job boards and continue to build your brand on these sites.

- Implement an applicant tracking system. A large number of vendors exist that provide applicant tracking systems in prices ranging from $\$ 1,000$ per month to more than $\$ 250,000$ per year. Centralizing your organization on a single platform will enable you to provide more meaningful measurements for your senior management.

- Create a peer-to-peer community with other like professionals in similar industries. Do not hesitate to network and call on them for their best practices.

\section{Looking forward}

The current US recession has set us back several years in building long-term recruitment strategies. Similar to a garden that is only weeded yearly, there are a lot of weeds that need to be cleaned out. Recent massive downsizing, generally done on the whim of Wall Street, should have been carefully planned and executed across the board (i.e., weekly weeding). Instead, it has resulted in severe damage for several prominent companies that have lost the trust, intregity, and commitment of their community of potential and past employees. Other companies that consistently manage (or weed) and measure their employees' performance and satisfaction have managed to escape relatively unscathed. For example, both General Electric and Metropolitan Life have put the proper measurements in place to rate all their employees to ensure that they retain their stars and eliminate their duds.

In order to compete for the best employees, companies need to integrate automated HR measurements with their recruitment and retention programs. Human resource departments will be able to deemphasize administrative tasks, and employers will be forced to become more accountable and move to an employee and managerial self-service platform (e.g., PeopleSoft or Employease). Also, portal implementation will be a big business driver that should be run by HR, as it touches all aspects of the organization, yet traditionally HR has not had the project management capabilities as the rest of the organization. Portals such as those from Workscape, SAP, and PeopleSoft enable users to access all the necessary data to get their jobs done from their desktop, including information on holidays, benefits, performance, company objectives, individual objectives, payroll, etc. The future of HR will be based on access to measurements and industry standards. HR needs a cooperative relationship with finance so these measurements can be integrated within a portal that can be delivered onto every employee's desktop. 